\title{
TRAUMATIC POSTERIOR DISLOCATION OF THE PAEDIATRIC HIP- A SERIES OF FIVE CASES
}

Bhupes Sil1 ${ }^{1}$, Ajay Kr. Goel2, Sankar Debroy ${ }^{3}$

${ }^{1}$ Assistant Professor, Department of Orthopaedics, AGMC and GBPH, Agartala, Tripura.

2Junior Resident, Department of Orthopaedics, AGMC and GBPH, Agartala, Tripura.

${ }^{3}$ Assistant Professor, Department of Orthopaedics, AGMC and GBPH, Agartala, Tripura.

\section{ABSTRACT}

\section{BACKGROUND}

Traumatic dislocation of the hip in paediatric age group is a rare injury. The purpose of this study is to report five such cases.

\section{Case Report}

Five cases of traumatic dislocation of the hip in children treated between 2009 and 2015 have been included in this study. All the five cases were boys with mean age of 6.12 years (range, 2 yrs. and 6 months to 10 years). Each of them had unilateral posterior hip dislocation. One of them also had associated shaft femur fracture on contralateral side. Four children underwent closed reduction under general anaesthesia within 6 hours of injury. In child with associated contralateral shaft femur fracture, dislocation was missed on the first instance which led to delayed reduction (around 15 hours). The limb was kept in skin traction on Thomas splint following reduction, which was continued for 3 weeks followed by physiotherapy and non-weight bearing exercise till 6 weeks. Gradual weight bearing allowed after 6 weeks. Hip spica was applied in case of associated shaft femur fracture 3 weeks post-traction for another 3 weeks. All patients showed good range of motion at 6 weeks post reduction.

\section{CONCLUSION}

Associated injuries of the ipsilateral/contralateral limb may lead to missing the diagnosis causing delay in management, so the patient should be examined thoroughly and should be re-examined if required.

\section{KEYWORDS}

Traumatic Dislocation, Early Closed Reduction, Paediatric Hip.

HOW TO CITE THIS ARTICLE: Sil B, Goel AK, Debroy S. Traumatic posterior dislocation of the paediatric hip - a series of five cases. J. Evolution Med. Dent. Sci. 2017;6(12):987-990, DOI: 10.14260/Jemds/2017/211

\section{BACKGROUND}

Traumatic dislocation of the hip in paediatric age group is a rare injury.[1],[2],[3] It has bimodal distribution.[4] Incidence is greater between 2 and 5 years of age due to joint laxity and soft cartilage and between 11 and 15 years of age because of athletic injuries and road traffic accidents.[4] Posterior dislocations occur due to axial load on flexed and adducted hip, while anterior dislocations occur with a combination of abduction and external rotation. ${ }^{[5]}$ The ideal management is a prompt diagnosis and reduction following which outcome is usually satisfactory. Here, we are reporting five cases of traumatic posterior hip dislocation in skeletally immature patients.

\section{MATERIALS AND METHODS}

Five cases of traumatic dislocation of the hip in children treated between 2009 and 2015 have been included in this study. Details of the patients are listed in Table 1.

Financial or Other, Competing Interest: None

Submission 11-06-2016, Peer Review 25-01-2017,

Acceptance 31-01-2017, Published 09-02-2017

Corresponding Author:

Dr. Bhupes Sil,

Type 4,

A/1 Govt. Quarters,

Gandhighat, Agartala,

Tripura (W)-799001

E-mail: bhupes1958@gmail.com

DOI: $10.14260 /$ jemds $/ 2017 / 211$

\section{(c) $($ ) $\$$}

\begin{tabular}{|c|c|c|c|c|c|c|}
\hline 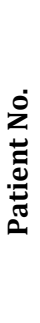 & $\underset{\varpi}{\sharp}$ & હે & 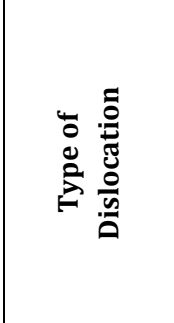 & 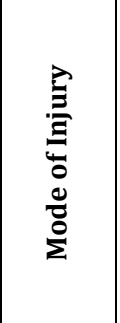 & 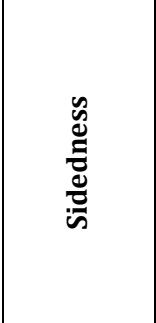 & 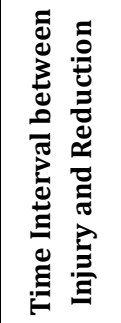 \\
\hline 1. & $\mid \begin{array}{c}2 \text { years } \\
6 \\
\text { Months }\end{array}$ & M & Posterior & $\begin{array}{c}\text { Fall } \\
\text { from } \\
\text { bed }\end{array}$ & Right & 5 hours \\
\hline 2. & $\begin{array}{c}3 \\
\text { years }\end{array}$ & M & $\begin{array}{c}\text { Posterior } \\
\text { dislocation } \\
\text { (left) } \\
\text { associated } \\
\text { with fracture } \\
\text { shaft femur } \\
\text { (right) }\end{array}$ & $\begin{array}{c}\text { Road } \\
\text { traffic } \\
\text { accident }\end{array}$ & $\begin{array}{c}\text { Dislocation } \\
\text { (Left) } \\
\text { Fracture } \\
\text { (Right) }\end{array}$ & 15 hours \\
\hline 3. & $\begin{array}{c}6 \\
\text { years }\end{array}$ & M & Posterior & $\begin{array}{c}\text { Fall } \\
\text { while } \\
\text { playing }\end{array}$ & Left & 6 hours \\
\hline 4. & $\begin{array}{c}9 \\
\text { years }\end{array}$ & M & Posterior & $\begin{array}{c}\text { Road } \\
\text { traffic } \\
\text { accident }\end{array}$ & Left & 5 hours \\
\hline 5. & $\begin{array}{c}10 \\
\text { years }\end{array}$ & M & Posterior & $\begin{array}{c}\text { Road } \\
\text { traffic } \\
\text { accident }\end{array}$ & Right & $\begin{array}{c}4 \text { hours } \\
30 \text { mins. }\end{array}$ \\
\hline
\end{tabular}

The limb was kept in skin traction on Thomas splint following reduction, which was continued for 3 weeks. Hip Spica was applied in case of associated shaft femur fracture 3 
weeks post traction for another 3 weeks. All patients showed good range of motion at 6 weeks post reduction.

\section{Illustrative Cases}

Two cases have been illustrated below by clinical photographs.

\section{CASE 1}

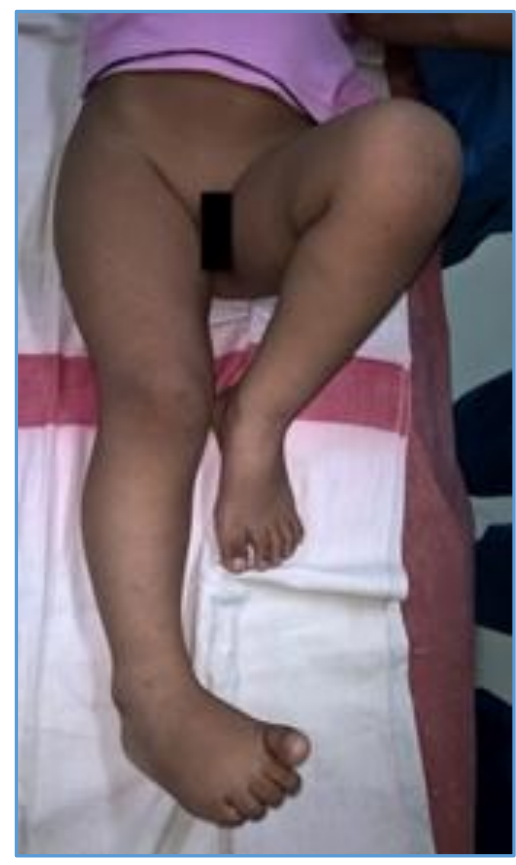

Figure 1. Flexion, Adduction and Internal Rotation

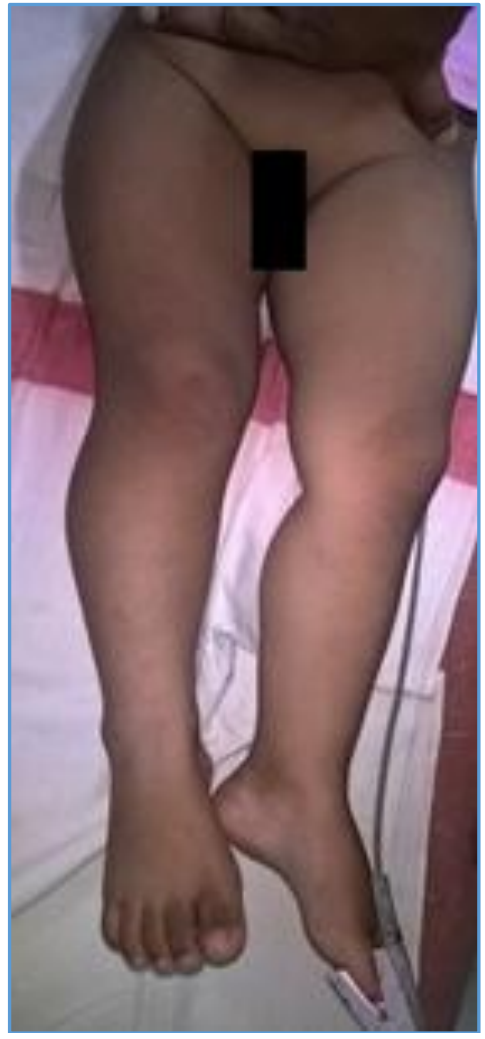

Figure 2. Apparent Shortening

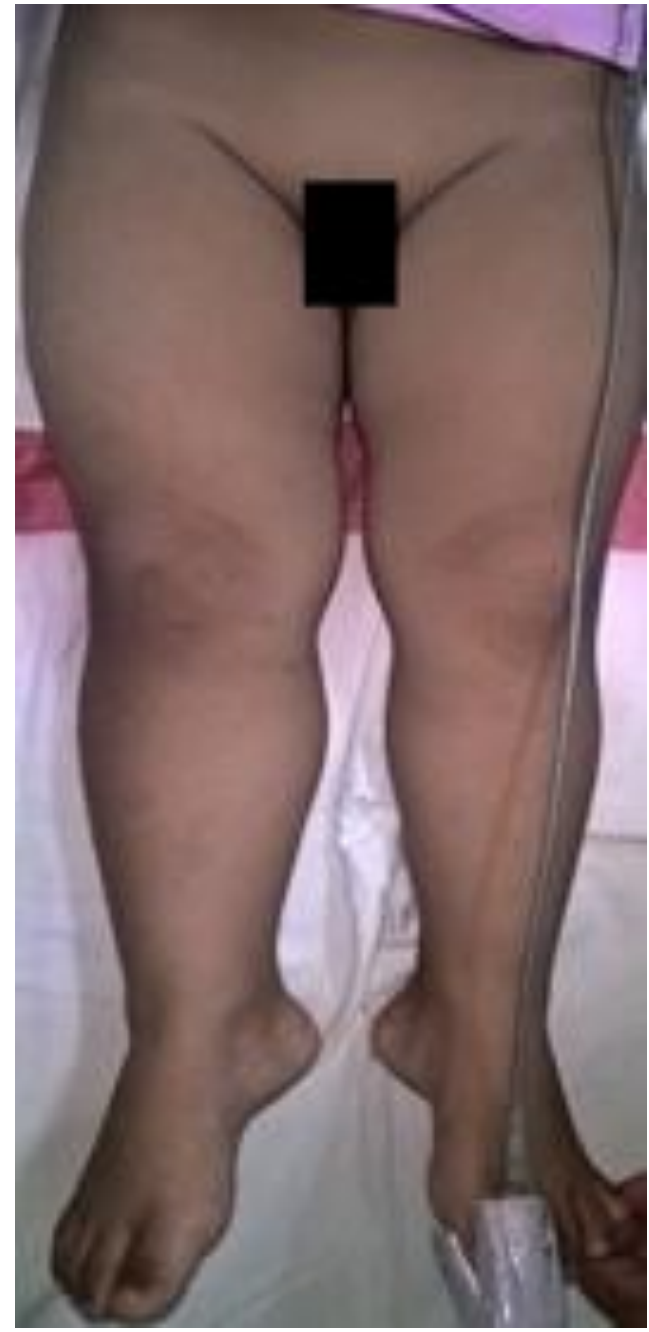

Figure 3. Post Reduction

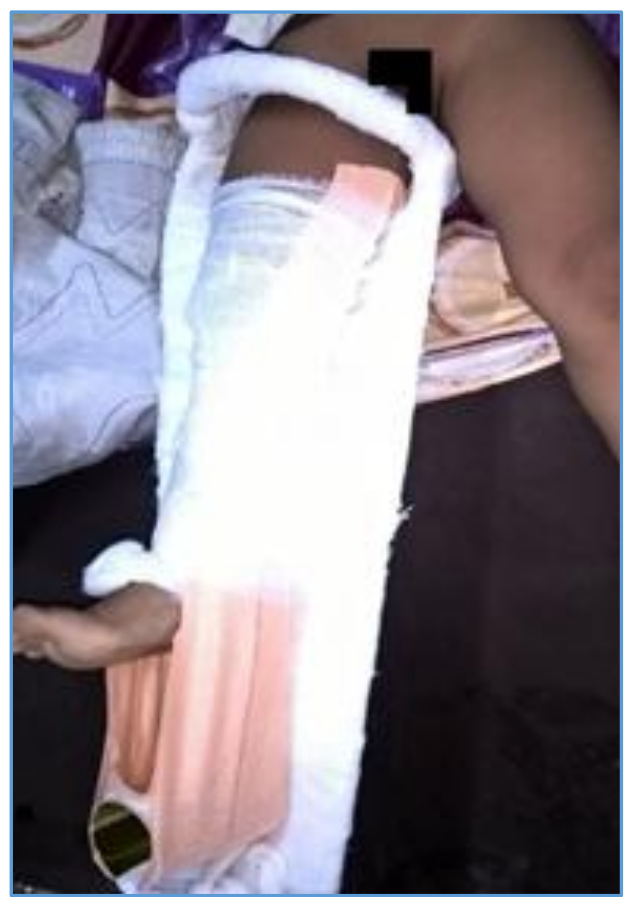

Figure 4. Surface Traction Immobilisation 


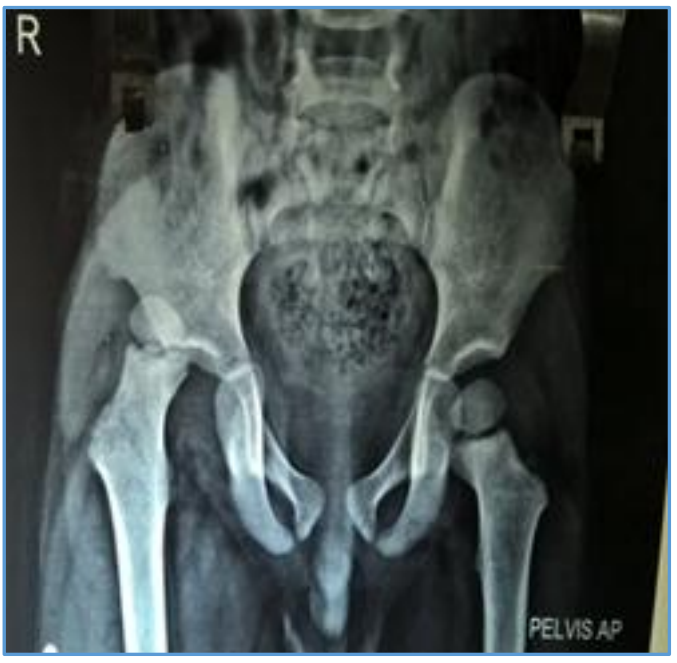

Figure 5. Pre-Reduction X-Ray

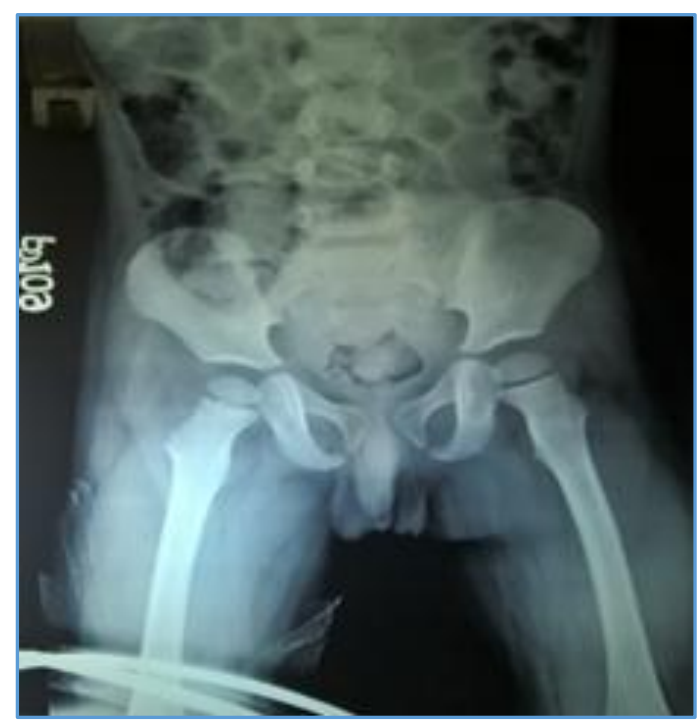

Figure 6. Post-Reduction X-Ray

\section{CASE 2}

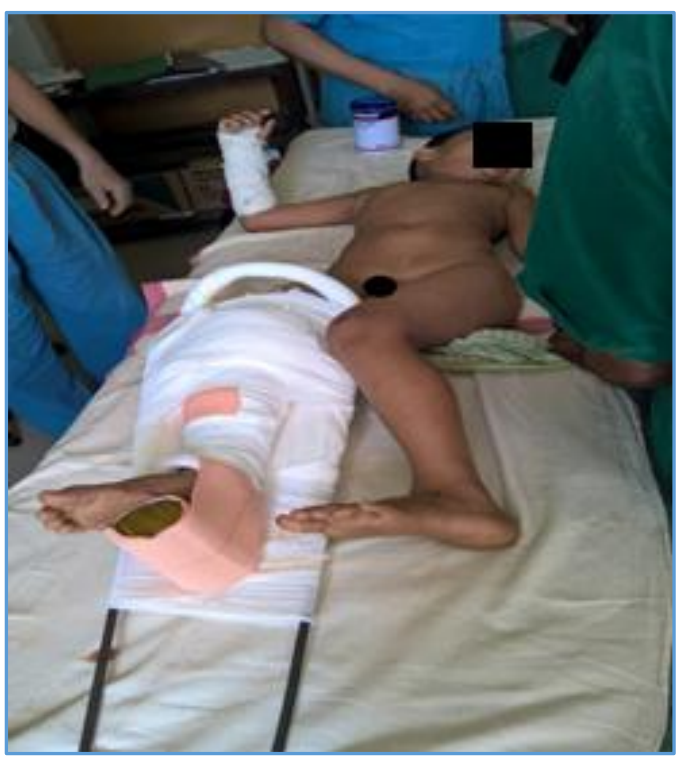

Fig 1: \# Shaft Femur in Thomas Splint (Rt.) and Missed Posterior Dislocation Hip (Lt.)

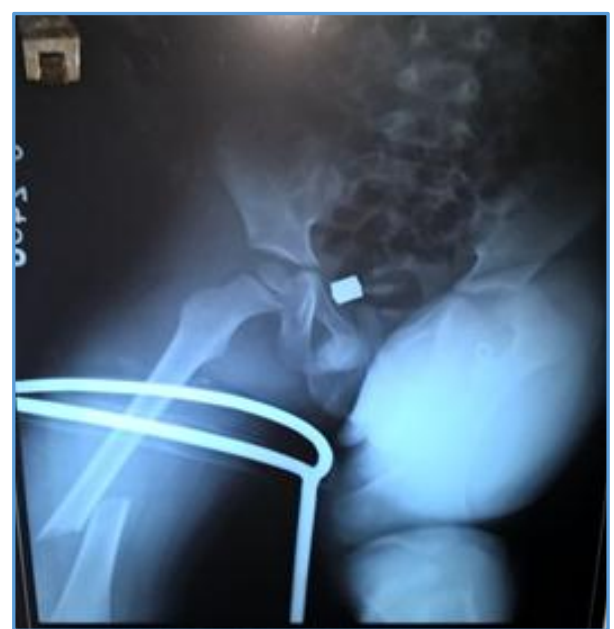

Fig 2: X-ray Showing \# shaft Femur (Rt.) and Missed Dislocation(Lt.) (not clear)

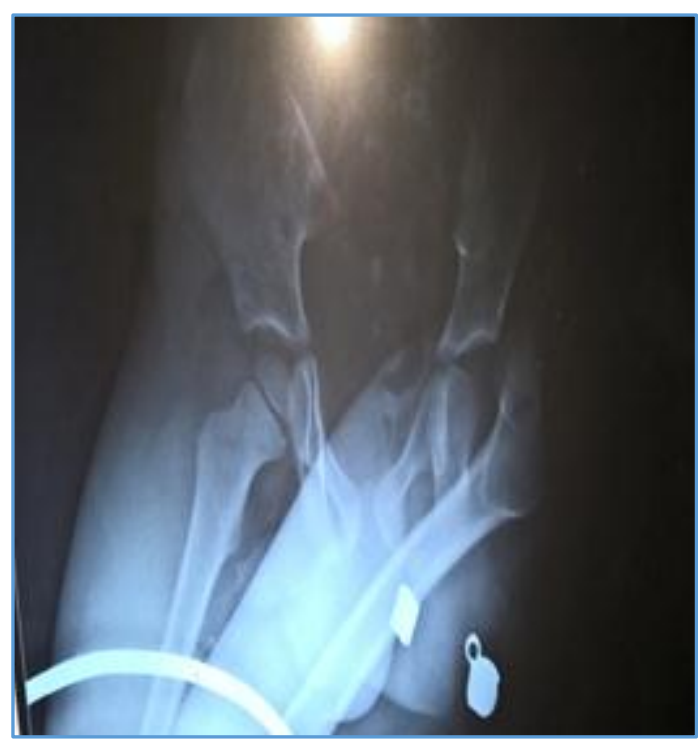

Figure 3. Repeat Radiograph shows Dislocation Hip Joint (Lt.)

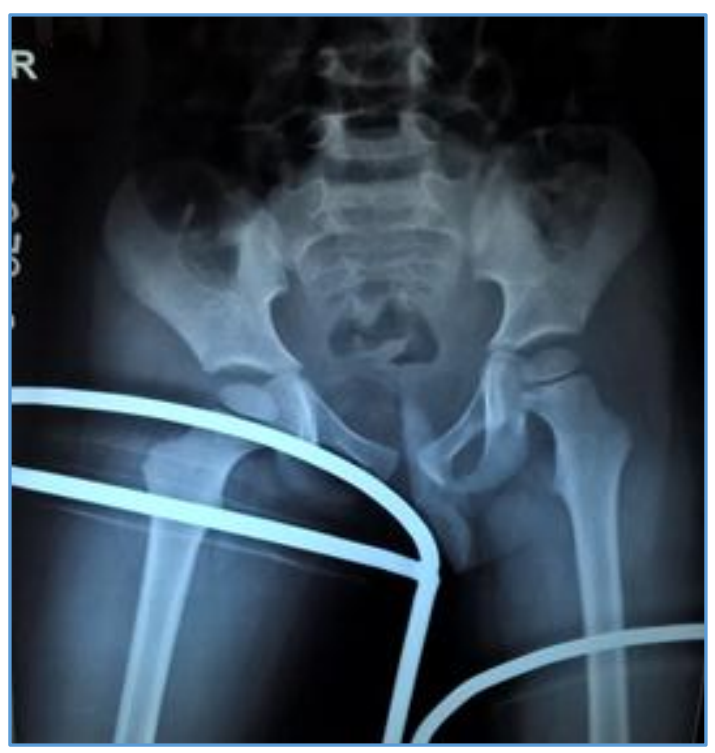

Figure 4. Post Reduction X-Ray 


\section{DISCUSSION}

A review of the literature shows that traumatic dislocation of the hip in children is a rare injury[1],[2],[3] and bilateral dislocation is almost an exception.[1],[6] It is seen that posterior dislocation is a commoner than anterior dislocation as in adults.[1],[7] In our study all the cases were of posterior dislocation and all the patients were boys indicating a predominance of male individuals as reported in the literature.[2],[6]

The hip is in flexion, adduction and internal rotation in posterior hip dislocation. ${ }^{[5]}$ The involved limb appears shorter than the contralateral limb and the femoral head can be palpated posteriorly in posterior type of hip dislocation. ${ }^{[8]}$

Even though the diagnosis is usually obvious, it is delayed or missed sometimes.[1],[2] The common cause for a delayed diagnosis is presence of another fracture or injury that diverts attention from the dislocated hip.[9],[10] Sciatic nerve injury may occur in $5 \%$ to $20 \%$ of cases.[3],[6],[9]

The treatment is immediate closed reduction under general anaesthesia. Rarely, open reduction may be required in failed cases of closed reduction either due to buttonholing of the femoral head through the hip capsule or due to infolding of the acetabular labrum.[2],[6],[11] Open reduction was not required in our series.

Good quality radiographs should be done post reduction to confirm a congruent reduction and to rule out any fracture. If in doubt, computed tomography should be done.

Majority of the authors recommend 6 weeks of immobilisation in traction or hip spica followed by weight bearing.

\section{CONCLUSION}

Associated injuries of the ipsilateral/contralateral limb may lead to missing the diagnosis causing delay in management, so the patient should be examined thoroughly and should be re-examined if required.

\section{REFERENCES}

[1] Bunnel WP, Webster DA. Late reduction of bilateral traumatic hip dislocations in a child. Clin Orthop 1980;147:160-3.

[2] Funk FJ. Traumatic dislocation of the hip in children: factors influencing prognosis and treatment. J Bone Joint Surg 1962;44(6):1135-45.

[3] Schlonsky J, Miller PR. Traumatic hip dislocations in children. J Bone Joint Surg 1973;55(5):1057-63.

[4] Egol KA, Koval KJ, Zuckerman JD. Handbook of fractures. $4^{\text {th }}$ edn. Philadelphia: LWW 2010:p 686.

[5] Beaty JH, Kasser JR. Rockwood and Wilkins fractures in children. Volume 3. $6^{\text {th }}$ edition. Lippincott Williams \& Wilkins 2006:p 880.

[6] Barquet A. Traumatic hip dislocation in childhood: a report of 26 cases and review of the literature. Acta Orthop Scand 1979;50(5):549-53.

[7] Endo S, Yamuda Y, Fujii N, et al. Bilateral traumatic hip dislocation in a child. Arch Orthop Trauma Surg 1993;112(3):155-6.

[8] Herring JA. Tachdjian's pediatric orthopaedics. WB Saunders, Philadelphia 2002:2273-83.

[9] Helal B, Skevis X. Unrecognised dislocation of the hip in fracture of the femoral shaft. J Bone Joint Surg 1967;49(2):293-300.

[10] Kumar S, Jain AK. Neglected traumatic hip dislocation in children. Clin Orthop 2005;431:9-13.

[11] Offierski CM. Traumatic dislocation of the hip in children. J Bone Joint Surg 1981;63-B(2):194-7. 